\title{
Challenges of Water Management towards Socio-Economic Development in Sub-Saharan Africa
}

\author{
Mamoloko F. Rachidi \\ University of Limpopo, Turfloop Graduate School of Leadership, \\ PO Box 759, Fauna Park; Polokwane 0787, Republic of South Africa \\ florah.rangongo@ul.ac.za or Mamoloko.Rangongo@hotmail.co.za
}

\section{Doi:10.5901/mjss.2014.v5n27p1391}

\begin{abstract}
This paper examines the challenges of water management towards Socio-economic development in sub-Saharan Africa. The specific objectives of the paper are to 1) review challenges associated with water management in Sub-Saharan Africa; and 2) indicate that water provision and management is a factor in socio-economic development of the region. The methodological approach for the paper is literature review. Water is a fundamental need for all humans, as well as all other living beings. Amongst other things, water provision and management is considered important for socio-economic growth and development as well as poverty alleviation. The Millennium Development Goals (MDGs) as one of the vehicles that can be used to promote socio-economic development were put together as a "global anti-poverty push". Attainment of the MDGs also needs effective water management and provision. By agreeing on the MDGs the world promised to reduce the number of people who do not have access to safe drinking water by half by 2015. The findings of the paper from the literature review indicate that many parts of the world are seemingly on their way to meeting the MDG water provision and management target, with the exception of most countries in sub-Saharan Africa. The situation is worse in rural areas where only about $50 \%$, compared to $80 \%$ of people in urban areas, have access to safe drinking water. It is expected that by 2015 at least 48 countries will be facing water shortages. About 22 of those countries are in Sub-Saharan Africa, indicating the need to keep water management as a priority in this region. This paper provides an overview of factors and/or challenges that impact on the management and delivery of water in sub-Saharan Africa as well as recommendations on improving the provision of water. Therefore, the paper demonstrates that water management remains a challenge and should be put on all agenda that are geared towards socioeconomic development.
\end{abstract}

Keywords: water management; water provision; Millennium Development Goals; socio-economic development; financial management

\section{Introduction}

The demand for fresh water is rising in response to global population expansion and industrialisation. Water is a basic human right and it is essential for the lives of humans, for development and for the environment in general (Lalzad, 2007; Nnadozie, 2011). However, water is a limited and vulnerable resource that is constrained in terms of quantity and quality. Shortage of water is becoming an international concern largely as a result of increasing population, economic growth and climate change. Efficient use of water, development of new sources of water as well as water conservation methods, should be important considerations of any country's national water plan. It was estimated that in 1995 there were 31 countries with a total population of 458 million which faced water stress. More worrying is the fact that it is estimated that over 2.8 billion people in 48 countries, including countries in sub-Saharan Africa, will face water stress by 2025, based on United Nations medium population projections (Lalzad, 2007).

Lalzad (2007) indicated that about $20 \%$ of the population of the world, i.e. about one billion people lack access to safe drinking water; over 50\% (3 billion) are without sanitation; and over $80 \%$ of all diseases and a little over one third of deaths in developing countries are linked to water. This further emphasises the need for every nation to take the issues of water seriously and prioritise them. Furthermore, about half of the rivers and lakes in the world have serious pollution, including pollution of waterways and surrounding river basins. Nearly half a billion people in 31 countries face water shortage problems and this is expected to increase to nearly two thirds of the world population by 2025. Two (2) in every 10 people on earth lack access to safe water supply. Many women and girls spend hours (often 4 to 6 hours) daily fetching and ferrying water, effectively precluding girls from attending school and getting an education (Lalzad, 2007; Stockholm International Water Institute [SIWI] Report; Nwankwoala; 2011).

Countries are also plagued by increasing water demands and occasions of declining and mismanaged water 
resources as well as inadequate water infrastructure. Degradation of freshwater ecosystems and land worsens the frequency and effect of droughts, floods and other natural hazards. This effect is more pronounced in areas that are ecologically fragile, where poor people often live, like in sub-Saharan Africa, and can increase the potential for people fighting over access to shared water resources. Internationally, water has shown to progressively be a scarce resource, and in sub-Saharan Africa water scarcity is a possible threat to local security (SIWI Report; Freitas, 2013).

The situation of water stress appears to be worse in sub-Saharan Africa. With only $36 \%$ of the population in this region having access to satisfactory hygienic water, sub-Saharan Africa is lagging way behind the average of the world at $58 \%$. This lag is even worse for the rural areas that are at $44 \%$ compared to $72 \%$ of the world's average access to safe water. Urban areas are a little better at $82 \%$ versus 95\% of the overall average (Carles, 2009; Nwankwoala, 2011). According to Carles (2009) the lack of access to water in sub-Saharan Africa is mostly an 'economic scarcity' rather than a 'physical scarcity'. Economic water scarcity means that the "human, institutional and financial capital limit access to water even though it is available locally to meet human demands... Therefore, sub-Saharan local populations do not have water because they are poor." (Carles 2009: 4).

This paper articulates a link between water and economic development and makes a case that it is essential to invest in water management for the alleviation of poverty. Good water supply and water resources management have a crucial link, directly and indirectly, on a country's overall economic development and growth and achievement of the Millennium Development Goals (MDGs). Current macroeconomic policies and decision making can be made more efficient and equitable if the economic benefits of improved water resources management and water supply and sanitation are factored into the economic development equation. Better access to clean water and sanitation creates remarkable opportunity for the poor people and is a good strategy for economic growth (Soussan, Noel, Harlin, \& Schmidt, 2009; SIWI Report).

This paper outlines the literature that indicates the challenges of water provision and management in sub-Saharan Africa, especially with regards to the attainment of the water provision MDG goal. Then conclusions are drawn and recommendations made.

\section{Literature Review}

Improved water supply and sanitation and efficient management of water resources enhances the economic growth of counties and contributes significantly to poverty alleviation. According to the Stockholm International Water Institute Report (SIWI) the economic benefits of good water supply and sanitation far outweigh the costs of investment. In addition, investing in water is good business as efficient management of water resources and water supply contributes considerably to better performance and productivity within economic sectors. This further highlights the importance of making water and related services a part of economic development processes.

Resolving water related challenges requires that the costs for improved water supply and sanitation and water resources management be seen as sound public and private investments and key to a strategy that boosts economies, enables individuals and businesses to explore new income opportunities and provides them with a fair chance to prosper. Water and economy are inextricably linked. In other words, water and related services like sanitation must be included in plans and discussions about economic development business (SIWI Report).

People in poor regions of the world, like Africa, benefit directly from better access to essential water and sanitation facilities by way of better health, avoiding health care costs and saving time. Interventions that enhance the supply of water and sanitation facilities can result in immediate and long-term socioeconomic and environmental gains that can make a significant difference to billions of people (SIWI Report). According to the World Health Organisation (WHO), for each dollar spent on safe drinking water, three to four dollars are generated, dependent upon the area and available technology. For sub-Saharan Africa, investing in water might be critical in achieving what the region strives for, the 'middle income' status by 2020 (Freitas, 2013).

Despite the progress made by some countries, Sub-Saharan Africa as a whole still lags behind most regions in the world when it comes to water access, management and supply (Freitas, 2013). According to the World Health Organisation (WHO), over 40\% of all people who do not have access to drinking water live in Sub-Saharan Africa (Freitas, 2013). The region is still faced with many challenges that hinder effective water supply, and therefore also hinder achievement of the set MDGs and development.

\subsection{The Contribution of Water toward the Millennium Development Goals}

The water-related challenges and the dire need to solve them have been confirmed at the highest political levels. It is 
agreed that water supply and effective management of water resources are essential for countries to be able to achieve each of the Millennium Development Goals (MDGs) (Rutten \& Mwangi, 2009; Soussan et al, 2006). The following table indicates how effective water supply contributes to attaining the MDGs.

Several authors have indicated how water can contribute to the achievement of MDGs (Rutten \& Mwangi, 2009; Soussan et al, 2006). Water is an important factor for production, especially in agriculture, which can boost regional development and alleviation of poverty. Girls and women often spend extended periods of time carrying and ferrying water to their homes. Access to water can help in empowering women to engage in other activities but most importantly it can afford girls more time to devote to school-related activities and thereby contribute towards achieving universal education. Improved safe water supply can reduce water-related diseases like diarrhoea, improve nutrition and food security and thus reduce child mortality. In addition, better water supply reduces vulnerability to certain illnesses and reduces labour burdens from water portage thereby improving maternal health.

In addition to the above, improved access to water can aid in health care programmes and improve early onset of Aids for instance. Mosquito habitats can also be reduced through better water management. Access to water and sanitation can help in preventing pollution of drinking water as well as maintain the ecosystem. Actions like recycling of waste water can also reduce water-borne pollution and subsequent environmental degradation. Fairer market conditions make exports from water-based production (e.g. irrigation) viable, generating greater pro-poor growth. Thus, investment in water management shows commitment to poverty alleviation (Rutten \& Mwangi, 2009; Soussan et al, 2006).

So while the rest of the world is making remarkable progress towards the attainment of the MDGs, sub-Saharan Africa and the developing world is most delayed by, amongst others, water supply and water management issues. These delays translate to delays in poverty reduction and regional economic development (Soussan et al, 2006).

\section{Findings from the Literature}

The study utilised literature review as a method of data collection. The following are key challenges that have been identified as hampering more effective water service delivery to the inhabitants of sub-Saharan Africa:

\subsection{Natural and/or Geographic Factors}

Despite the rain, long rivers, great lakes and vast shores, water in Sub-Saharan Africa is not evenly distributed across the region. The distribution ranges from very dry countries such as Mauritania, Niger or Botswana for instance to very humid ones in Central and Western Africa. In addition, climatic conditions and environmental changes have remarkably reduced fresh water quantity resulting in most countries in the region being under severe water stress. The region of sub-Saharan Africa experiences droughts in some areas and floods in others (at different times of the year). Managing the devastating effects of droughts or floods also takes a lot of time and effort from the already overburdened economy of the region. In addition, the growing scarcity of water can also be attributed to shrinking of some water bodies as well as desertification (Carles, 2009; UN Water/Africa Report; Freitas, 2013).

The sub-Saharan region also lacks sustainable water sources for future supply of its inhabitants. In addition, a lot of major cities tend to depend on water transported from outside their jurisdiction. Transporting water is also faced with challenges of pipes that get damaged resulting with up to between $50 \%$ and $80 \%$ of unaccounted water loss in some instances. This water loss is relatively very high compared to only $10-20 \%$ of unaccounted water loss in developed countries (K'Akumu, 2007; Lalzad, 2007; Polokwane IDP 2013/5).

\subsection{Socioeconomic Factors}

The economic growth in Africa has also exacerbated the problem of water quality and quantity as the growth is primarily based on the exploitation of natural resources. Most of sub-Saharan Africa depend on agriculture as the major economic driver. Unfortunately agriculture is also a great user of water, utilising about an average of $86 \%$ use of national water. Agriculture also results in deforestation wherein arable land is exploited, pesticides and fertilisers are used as well as land for breeding animals. Deforestation is also through relentless harvesting of sand alongside rivers, which is also a problem as sand helps with the growth and sustenance of vegetation on river banks helping with the ecosystem in those areas as well as water not evaporating too easily (Rutten \& Mwangi, 2009; Carles 2009; van Koppen, Namara, \& SafiliosRothschild, 2005).

Pollution and the degradation of the environment also pose a challenge for safe water supply in sub-Saharan Africa. The dumping of industrial sewage and waste as well as unrestrained utilisation of agro-chemicals and oil spills are 
common in this region. "The sedimentation and discharge of municipal, industrial and agricultural effluent in Lake Victoria, the massive oil spills on Nigeria's coasts or lead poisoning cases due to gold mining operations in South Africa all seek to highlight the fact that combatting water pollution requires the active engagement of both local and international investors". In addition, these mentioned issues also highlight the fact that water management should be a concerted effort from multiple sectors (Freitas, 2013: 2).

There is also the issue of growing populations due to rapid urbanisation experienced in sub-Saharan Africa, which is expected to exacerbate the problem of water shortage. There is an unrelenting influx of people into urban areas, increasing the challenges on the already overburdened water supplies (Rutten \& Mwangi, 2009), i.e. there is continuous increase of new settlement areas in and around the cities, some of these settlement areas are unplanned and unbudgeted for (Polokwane IDP 2013/5; Freitas, 2013). In some countries, such as Kenya for instance, new large scale settlements and commercial cultural activities have resulted in sinking of many deep boreholes that are draining the aquifers and reducing the quality of water resulting in the destruction of the sustenance of groundwater (Rutten \& Mwangi, 2009).

Like most other parts of the world, especially the developing world, sub-Saharan Africa is also faced with healthrelated challenges that are water related (Lee \& Schwab, 2005). For instance diseases like malaria that are water-related "kill more than 5 million people each year in the world, most of them in sub-Saharan Africa" (Carles 2009). Almost half of all Africans suffer from water-borne illnesses, with cholera and infant diarrhoea being the most frequently occurring illnesses (World Water Assessment Programme, 2009). According to Freitas (2013) most of the countries with the lowest levels of sanitation are in sub-Saharan Africa and poor sanitation is very much related to water-borne diseases.

\subsection{Technical Factors}

Most places in sub-Saharan Africa have ageing water infrastructure, i.e. pipes, wells and boreholes with limited operation and maintenance of such infrastructure. Complicating the problem of inadequate infrastructure are the issues of theft and vandalism of piping and other structures of boreholes and reliable surface water that are common (Lee \& Schwab, 2005; Rutten \& Mwangi, 2009; Polokwane IDP 2013/5).

The majority of the urban areas and towns are not built next to major water sources. As a result, water has to be transported to such areas resulting in problems of water loss through leaking pipes. Reticulation leaks are also contributory to water losses (K'Akumu, 2007; Freistas, 2013; Polokwane IDP 2013/5).

\subsection{Political and Institutional Factors}

Some countries in Sub-Saharan Africa still experience violent conflict over water resources (like the 2005 disputes over water shortages in the Rift Valley of Kenya, or Tanzania and Malawi's dispute over rights to Lake Malawi or the dispute over the use of Lake Chad's waters despite the Lake Chad Basin Commission (created in 1964). These conflicts complicate the issue of water management and supply (Rutten \& Mwangi, 2009; Freistas, 2013). Again, some of the countries in the region are still plagued by the problem of 'land-grabbing'. This land-grabbing is usually for waterdemanding agricultural activities that are often coupled with deforestation further jeopardising water supplies (Freistas, 2013).

Most of the regions lack effective cost recovery mechanisms especially in their rural areas, i.e. ineffective collection of revenue. In addition, metering is not done efficiently, either the installation of water meters or the reading of those meters and subsequent charging for service provided. The rural households that get water from in front of their yards or share communal water do not pay for the water service. In addition, although some rural areas have meters in the yards they are still not charged for the water service. Another problem in rural areas is that of illegal connections and reticulation leaks that cause loss of water (K'Akumu, 2007; Polokwane IDP 2013/5).

There is also a challenge of human factors include depletion of water resources through for instance, pollution, environmental degradation and deforestation. According to the UN Water/Africa Report Africa is still faced with issues of unacceptable governance and unsatisfactory institutional arrangements in terms of the management of water generally and the management of national and transactional water basins. There is no adequate investment in financing of water supply and sanitation. Regardless of strong political commitments to improved water supply and management, and the strong demand for improvements from communities throughout developing regions, access to water remains insufficient. Furthermore, there is limited awareness of the contribution of water to economic development (SIWI Report; K'Akumu, 2007). In addition to the diminishing quantity of water in the region, there is also a problem of poor quality of water. As a result of pollution and poor sanitation facilities only a small proportion of the water that is available is of drinking quality 
(Freitas, 2013).

Although legislation is in place in most situations, a lot of countries in the region still very much lack the resources and the expertise required to assess water use and demand and enforce regulations. The countries also experience limited funds and inadequate technical support and/or advice. There is also a problem of lack of skilled personnel in terms of financial skills for collection of revenue, technical skills in terms of installation and maintenance of infrastructure and impact assessment skills (Rutten \& Mwangi, 2009; Polokwane IDP 2013/5).

\section{Recommendations}

The study makes the following recommendations for improved water management and water supply:

\subsection{Management and governance issues}

Sub-Saharan Africa as a region still has political and governance challenges that hamper efficient water supply and water management. Therefore, the region should consider instituting and developing skilled managers who develop policies and procedures that need to be followed to provide and manage water as well as implement policies that are already in place and monitor their progress. Particular attention should also be paid to financial skills/expertise as well as technological skills as developments in technology require skills in that area. Training and/or hiring of personnel working in the provision of water services in the management of the service should the need arise. This implies that a skills audit may need to be conducted to especially look at policy, financial and strategic management issues as well as technology within the water supply services.

Together with acquiring and developing relevant skills, countries and organisations should allocate enough financial resources towards water supply and management. The finance is to be used for skills training and development; retaining qualified and experienced personnel; upgrade of old and ageing infrastructure, purchasing of new and modern equipment that is in line with modern technology.

Water management should be a multi-sector effort that includes for instance environmental maintenance and management as well as inclusion of the economic and finance section/activities of all countries. Virtually all discussions and plans about development should include water management and supply.

An enabling environment for cooperation between countries that share international water basins should also be created. Adequate budget for the complete replacement and maintenance of the ageing water infrastructure should be provided. Countries in the region should investigate better technology that can help in the pumping and transportation of water to help with unnecessary water loss.

Instead of only attempting to increase water supply, intelligent water conservation and demand management programmes can be looked at as well as installing new efficient equipment and applying appropriate economic and institutional incentives to optimise water usage can be considered. New equipment and infrastructure may alleviate, amongst others, the challenge of unaccounted water loss.

Economic growth and activities as well as population growth challenge the management of water. Therefore, population growth analyses should be conducted to determine more realistic water demand and plan for that demand more efficiently.

\subsection{Water Wisdom}

The people of the sub-Saharan region can be encouraged to consider the traditional approaches of for instance constructing wells, dams, reservoirs and pumps to collect, control and contain excess flows of water and to distribute water on demand during different periods. In addition, water use and/or conservation awareness campaigns should be increased as well as an emphasis on using water sparingly, water recycling and harvesting. Africans do not seem to be fully aware of the fact that their country is a water scarce area and what that really implies for the future.

\section{Conclusion}

Water is without doubt an important factor in the socio-economic development of sub-Saharan Africa. The area has regions that are rich with water supplies as well as drier ones. This paper indicates that to achieve the MDG goal of providing water to all in sub-Saharan Africa is an important but not easy task given the challenges outlined as well as the complex nature of this region. This task needs the involvement and cooperation of different countries, which share 
waters, as well as various departments and individuals within countries. It also involves acknowledgement of the fact that water management is a long-term, if not life-long commitment by all involved stakeholders. Water provision is also crucial for attainment of most of the other MDGs and is thus critical for overall socio-economic development of any region of the world, sub-Saharan Africa included. Water provision should also involve sustainable utilisation and management of the available water resources and the environment, as well as regional cooperation. Another challenge is availability of finance to implement all the requirements of a sustainable water supply service in the area. A framework for action needs to be put in place, where available revisited, implement and monitored regularly.

\section{References}

Carles, A. (2009). Water resources in sub-Saharan Africa. Paper prepared for the "Peace with Water" conference, 12 - 13 February, Brussels, Belgium.

Freitas, A. (2013). Water as a stress factor in sub-Saharan Africa. European Union Institute for Security Studies.

K'Akumu, O. A. (2007). Toward effective governance of water services in Kenya. Water Policy, 9, 529 -543.

Lalzad, K. (2007). An Overview of the Global Water Problems and Solutions. Available from: http://gotaman.com [Accessed: 26 February 2014].

Lee, E. J. \& Schwab, K. J. (2005). Deficiencies in drinking water distribution systems in developing countries. Journal of Water and Health, 3 (2), 109 - 127.

Nnadozie, R. C. (2011). Access to adequate water in post-apartheid South African provinces: an overview of numerical trends. Water SA, 37 (3). Available from: http://scielo.org.za. [Accessed: 27 February 2014].

Nwankwoala, H. O. (2011). Localizing the strategy for achieving rural water supply and sanitation in Nigeria. African Journal of Environmental Science and Technology, 5(13),1170-1176

Polokwane Municipality Integrated Development Plan (2012- 2013/15). Polokwane, Limpopo Province, South Africa.

Rutten, M. \& Mwangi, M. (2009). Ignoring another inconvenient truth? Challenges in managing Africa's water crisis. African Studies Centre, Kenya.

Soussan, J., Noel, S., Harlin, J. and Schmidt, S. (2009). Linking poverty reduction and watermanagement. S.I.: Poverty-Environment Partnership (PEP).

UN WATER/AFRICA. The Africa water vision for 2025: Equitable and sustainable use of water for socioeconomic development. Economic Division for Africa, Addis Ababa, Ethiopia.

Van Koppen, B., Namara, R. \& Safilios-Rothschild, C. (2005). Reducing Poverty through investments in Agricultural water management: Poverty and gender issues and synthesis of sub-Saharan Africa case study reports. Working paper 101. Final ReportSubmitted by the International Water Management Institute (IWMI).

World Water Assessment Programme. (2009). The United Nations World Water Development Report 3: Water in a Changing World. Paris: UNESCO, and London: Earthscan. 